\title{
Domingo Álvarez Enciso: redes de apoyo e influencias
}

\author{
Myriam FerReIRA*
}

\author{
DOMINGo ÁlVAREZ ENCISO: REDES DE APOYO E INFLUENCIAS
}

\section{Resumen}

El pintor Domingo Álvarez Enciso fue uno de los alumnos de la Real Academia de Bellas Artes de San Fernando enviados como pensionados a Roma entre 1758 y 1764. Su figura había sido tratada por diversas publicaciones recientes, en especial tras descubrirse su Taccuino o cuaderno de dibujo en el Museu Nacional d'Art de Catalunya. Sin embargo, eran varias las lagunas que existían en su vida, además de que algunos datos citados habitualmente - como el año y el lugar de su nacimiento o la fecha de su muerte- no eran correctos. En este trabajo se intenta rellenar esas lagunas, aunque centrándonos sobre todo en un aspecto: los apoyos que facilitaron sus viajes y su establecimiento en Roma, con el fin de ir completando el mapa de contactos entre los artistas españoles en Italia.

\section{Domingo Álvarez ENCISO: Support Networks AND INFLUENCES}

\section{Abstract}

The Spanish painter Domingo Álvarez Enciso was one of the students that the Real Academia de Bellas Artes de San Fernando sent to Rome on a scholarship between 1758 and 1764. He has been the subject of several recent publications, especially after the discovery of his Taccuino, or sketchbook, in the Museu Nacional d'Art de Catalunya. However, there were still some gaps in his biography, and the fact that some commonly cited data (such as his birth year and place, and date of death) were not correct. This paper attempts to fill in these gaps, while focusing especially on the support he had on his travels and while establishing himself in Rome, with the aim of completing the map of contacts between Spanish artists in Italy.

Ferreira, M., «Domingo Álvarez Enciso: redes de apoyo e influencias», Acta/Artis. Estudis d'Art Modern, 6, 2018, págs. 131-143

Palabras Clave: Domingo Álvarez Enciso, siglo XviII, pintor, Real Academia de Bellas Artes de San Fernando, pensionados, Roma

KEYworDs: Domingo Álvarez Enciso, eighteenth century, painter, Real Academia de Bellas Artes de San Fernando, pensionnaires, Rome

\footnotetext{
* Este trabajo se enmarca en el proyecto de investigación ACAF/ART IV «Cartografías analíticas, críticas y selectivas del entorno artístico y monumental del área mediterránea en la edad moderna» (HAR201566579-P), financiado por el Ministerio de Economía y Competitividad.
} 
Domingo Álvarez Enciso fue un pintor español que formó parte del grupo de pensionados que envió la Real Academia de San Fernando a Roma entre 1758 y $1764 .{ }^{1}$ Sin embargo, a diferencia del resto de los pensionados de su grupo, apenas desarrolló su carrera artística en España; por el contrario, mantuvo una gran vinculación con Roma, adonde regresó en cuatro ocasiones más, y vivió allí un total de casi veinticinco años. En este trabajo analizaremos las causas de esos continuados viajes entre Roma y España y los contactos en los que fue apoyándose en ambos lugares.

\section{NACIMIENTO E INFANCIA (1736-1747)}

Domingo Álvarez Enciso, hijo de Juan Antonio Álvarez Enciso y de Teresa Sáinz Alfaro, nació el 19 de diciembre de 1736 en Ventrosa, entonces provincia de Burgos y hoy parte de La Rioja. ${ }^{2}$ Con tres años aproximadamente se trasladó a Mansilla de la Sierra, donde estaba asentada su familia (ilustración 1). Al parecer se trataba de una familia acomodada y pertenecían al estado noble: su padre era cirujano, por lo que desempeñaba una profesión liberal, ${ }^{3}$ y dos hermanos de su madre, Agustín y Manuel Sáinz Alfaro, trabajaban en la corte, en concreto al servicio del rey en la Real Furriera. Además, varios miembros de su familia destacaron en los negocios: un tío suyo, Pedro Álvarez, emigró a América, donde se hizo con una hacienda en México; ${ }^{4}$ un primo suyo, Fernando Álvarez, fue oficial de la Mesa de Comercio de los Cinco Gremios Mayores de Madrid; ${ }^{5}$ y otro primo, Ambrosio Álvarez, fue oficial de la Administración General de la Real Gracia del Excusado del Reyno de Aragón. ${ }^{6}$ En cambio, no tenemos constancia de que ningún miembro de la familia se hubiera formado o trabajara como artista. ${ }^{7}$

1. Sobre las publicaciones que más se han centrado en la figura de Domingo Álvarez podemos citar MuÑoz y MANZANO, C. (VIÑ̃ZA, Conde DE LA), Adiciones al diccionario histórico de los más ilustres profesores de las Bellas Artes en España de D. Juan Agustín Ceán Bermúdez [facsímil del original de 1889-1894], 4 vols. Madrid: Atlas, 1972, vol. I , pág. 15; OssoRIO Y BERNARD, M., Galería biográfica de artistas españoles del siglo XIX, 2 vols. Madrid: Ramón Moreno, 1868, vol. I, págs. 24-25; Morales Marín, J.L. (coord.), Los pintores de la Ilustración, cat. exp., Centro Cultural del Conde Duque, Madrid, 1988. Madrid: Ayuntamiento de Madrid, 1988, págs. 203-205; ConTento MárQuez, R. (coord.), Formación del buen gusto. Dibujos de pensionados en Roma (1752-1786), cat. exp., 17-31 de mayo de 1995, Facultad de Bellas Artes de la Universidad Complutense de Madrid. Madrid: Universidad Complutense de Madrid, Facultad de Bellas Artes, 1995, págs. 31 y 32; URREA FERNÁNDEZ, J., Relaciones artísticas hispano-romanas en el siglo XVIII. Madrid: Fundación de Apoyo a la Historia del Arte Hispánico, 2006, pág. 182; CRUZ AlCAÑIZ, C., «Entre la fortuna y el olvido. La actividad pictórica del pensionado romano Domingo Álvarez (1739-180o)», Atrio. Revista de Historia del Arte, 13-14, 2007-2008, págs. 53-70; ConTENTo, R., «Domingo Álvarez Enciso», en SuREDA, J. (coord.), Goya e Italia, cat. exp., 1 de junio - 15 de septiembre de 2008, Museo de Zaragoza, Zaragoza, 2 vols. Madrid: Fundación Goya en Aragón - Turner, 2008, vol. 1, págs. 249 y 250; FeRnÁNDEZ BASTOS, L., «Álvarez Enciso, Domingo», en ANES, G. (dir.), Diccionario biográfico español, 50 vols. Madrid: Real Academia de la Historia, 2009, vol. III, págs. 538 y 539; SuREDA, J., «Sobre el viaje a Roma. El caso de Domingo Álvarez Enciso», en MARCH, E.; NARVÁEZ, C. (coords.), Narratives biogràfiques en la Història de l'Art, Seminario Internacional de Investigación, 19-22 de octubre de 2011, Facultat de Geografia i Història, Universitat de Barcelona, conferencia pronunciada el 21 de octubre de 2011, archivo audiovisual disponible en www.ub.edu/ubtv_proves/ es/video/sobre-el-viaje-a-roma-el-caso-de-domingo-alvarez-enciso [fecha de consulta: 4 de octubre de 2017].

2. Archivo Histórico Diocesano de Logroño (AHDL), Ventrosa, Bautizados, libro 4, 1725-1785, fol. 50v.

3. En la partida de nacimiento de Domingo se dice de su padre que era «asistente en esta d[ic]ha v[ill]a de Ventrosa p[o] r cirujano"; AHDL, Ventrosa, Bautizados, libro 4, 1725-1785, fol. 50v.

4. Universidad de Texas - Centro Dolph Briscoe de Historia Americana, carta de Pedro Álvarez Enciso a Fernando Álvarez Enciso, 6 de marzo de 1769, fol. 2r., disponible en www.cah.utexas.edu/projects/bexar/docs.php?type=c\&date=1769 [fecha de consulta: 17 de noviembre de 2017].

5. «Lista de los señores subscriptores a la Historia General de España del p. Juan de Mariana», en MARIANA, J., Historia general de España. Valencia: Benito Monfort, 1783.

6. Álvarez Enciso, A., Discurso sobre las ventajas que pueden proporcionar a el estado las Sociedades Económicas de los Amigos del País, con el fomento de la agricultura, artes y comercio. Zaragoza: Juan Ibáñez, 1784.

7. La única excepción será su recién citado primo Ambrosio, quien se matriculó en la Real Academia de Bellas Artes de San Fernando, pero ya en 1766, bastante más tarde que Domingo: PARDo CANALís, E., Los registros de matrícula de la Academia de San Fernando de 1752 a 1815. Madrid: Consejo Superior de Investigaciones Científicas, 1951, pág. 6. 


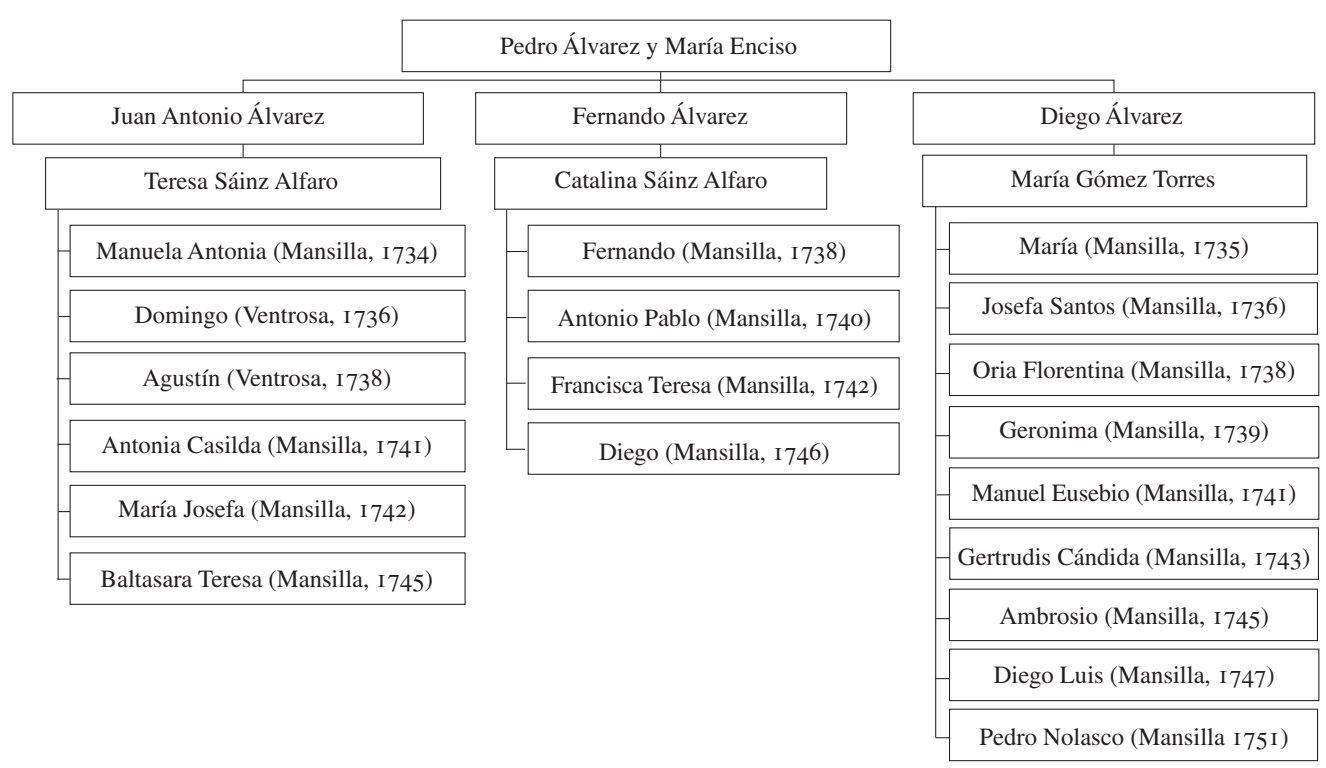

1. Árbol genealógico de la familia Álvarez Enciso.

PRIMERA FORMACIÓN ARTÍstica (1747-1758)

En 1747, con once años, Domingo se trasladó a Madrid con su familia. ${ }^{8}$ De hecho, la documentación indica que poco a poco fueron abandonando Mansilla todos los Álvarez Enciso, tal vez porque la capital les ofrecía buenas perspectivas, dado que tenían familiares en la corte. Quizá por medio de estos familiares, Domingo conoció al pintor Andrés de la Calleja, que también trabajaba en la Real Furriera y que posiblemente tuviera cierta cercanía con los Sáinz Alfaro, porque procedía también de la sierra riojano-burgalesa. ${ }^{9} \mathrm{Y}$ es probable que Domingo se sintiera atraído por la actividad del pintor y por ese motivo acabara entrando a formarse en su taller. ${ }^{10}$

El 16 de octubre de 1752 el joven se matriculó en la recién fundada Real Academia de Bellas Artes de San Fernando, a la que Calleja se había incorporado como profesor. ${ }^{11}$ Domingo se fue presentando a los concursos que se organizaban en esta institución, aunque solo fue premiado en uno de ellos (ilustración 2). ${ }^{12}$ Simultáneamente, Calleja le fue dando encargos como dibujante en la Real Fábrica de Tapices, para la que él trabajaba. ${ }^{13}$ En 1758 Domingo Álvarez participó en un nuevo concurso en la Academia: una convocatoria para enviar pensionados a formarse en Roma. Y en esta ocasión la suerte le favoreció, pues obtuvo el primer puesto en la clase de pintura. ${ }^{14}$

8. Archivio Storico del Vicariato di Roma (ASVR), Dossieres matrimoniales, Bernardino Monti, 1767, s/f. En este documento declaraba «esser partito dalla sua Patria l'anno 1747: in età di anni 11 con essersi portato in Madrid».

9. Morales Piga, M.L., Andrés de la Calleja, tesis doctoral. Facultad de Geografía e Historia, Universidad Complutense de Madrid, 1994.

10. Archivo de la Real Academia de Bellas Artes de San Fernando (ARABASF), Libro de actas, 1757-1769, leg. 3-82, fol. $28 \mathrm{v}$.

11. ARABASF, Libro de matrícula, 1752-1778, leg. 3-300, fol. 24r.; PARDo CANALís, E., Los registros de matrícula..., pág. 7 . 12. ARABASF, Libro de actas, 1752-1757, leg. 3-81, fol. 34r, 43r-44v, 58v-59v; LóPEZ DE MENESES, A., «Las pensiones que en 1758 concedió la Academia de San Fernando para ampliación de estudios en Roma», Boletín de la Sociedad Española de Excursiones, 41, 1933, págs. 261-263; CRUz AlCAÑIz, C., «Entre la fortuna...», pág. 54.

13. Morales Piga, M.L., "Andrés de la Calleja, autor de los cartones para la Pieza de Café del Palacio de El Pardo», Academia: Boletín de la Real Academia de Bellas Artes de San Fernando, 75, 1992, pág. 440; Morales PigA, M.L., Andrés de la Calleja..., pág. 249.

14. López De Meneses, A., «Las pensiones...», págs. 268-271; Contento MáRQuez, R., Formación del buen gusto..., pág. 25; Cruz AlCaÑIZ, C., «Entre la fortuna...», pág. 54. 
2. Participación

de Domingo

Álvarez Enciso

en los concursos

de la Real

Academia

de Bellas Artes

de San Fernando.

\begin{tabular}{|c|c|c|c|c|}
\hline $\begin{array}{l}\text { AÑO DEL } \\
\text { CONCURSO }\end{array}$ & TIPO DE CONCURSO & $\begin{array}{l}\text { TEMA DE LA PRUEBA } \\
\text { DE PENSADO }\end{array}$ & $\begin{array}{l}\text { TEMA DE LA PRUEBA } \\
\text { DE REPENTE }\end{array}$ & Resultado \\
\hline 1754 & Premios generales & Hércules Farnesio & Gladiador & $\begin{array}{l}\text { Primer premio } \\
\text { de tercera clase } \\
\text { de pintura }\end{array}$ \\
\hline 1756 & Premios generales & $\begin{array}{l}\text { Suintila expulsa } \\
\text { a los bizantinos } \\
\text { de la Península }\end{array}$ & $\begin{array}{l}\text { La pelea entre } \\
\text { don Pedro I } \\
\text { y don Enrique } \\
\text { de Trastámara }\end{array}$ & $\begin{array}{l}\text { Sin premio } \\
\text { en la segunda clase } \\
\text { de pintura }\end{array}$ \\
\hline 1757 & Premios generales & $\begin{array}{l}\text { Fernando III } \\
\text { entra a Sevilla } \\
\text { a hacer oración } \\
\text { ante la Virgen }\end{array}$ & $\begin{array}{l}\text { Fernando III rechaza } \\
\text { los cálices que le } \\
\text { ofrece un obispo } \\
\text { de Sevilla }\end{array}$ & $\begin{array}{l}\text { Sin premio } \\
\text { en la segunda clase } \\
\text { de pintura }\end{array}$ \\
\hline 1758 & $\begin{array}{l}\text { Oposición } \\
\text { para seleccionar } \\
\text { a los pensionados } \\
\text { en Roma }\end{array}$ & \multicolumn{2}{|c|}{$\begin{array}{l}\text { Pedro Ansúrez se presenta ante Alfonso } \\
\text { el Batallador después de haber entregado } \\
\text { todas sus posesiones a la reina Urraca } \\
\text { que este había repudiado }\end{array}$} & $\begin{array}{l}\text { Premio } \\
\text { en la categoría } \\
\text { de pintura }\end{array}$ \\
\hline
\end{tabular}

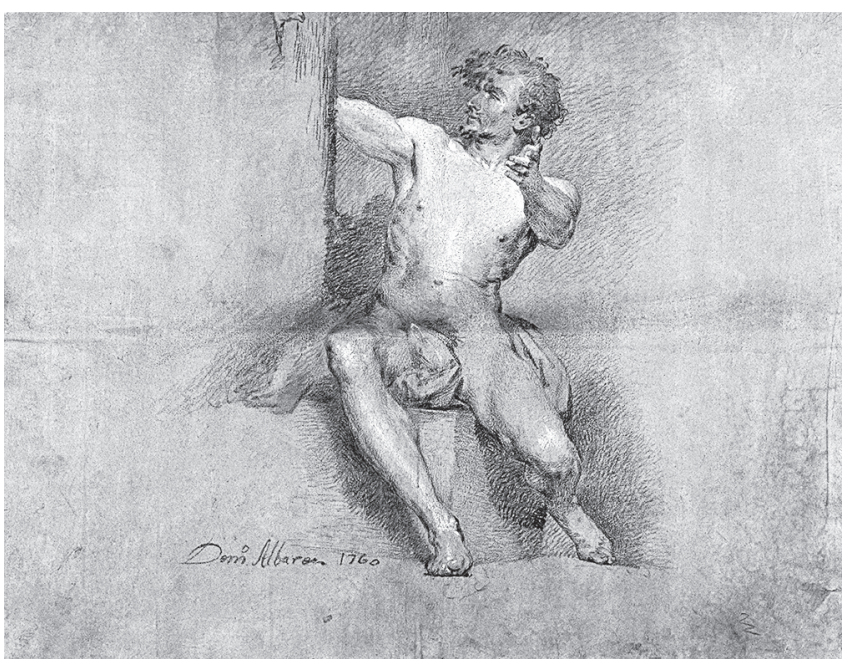

\section{Primera estancia en Roma (1758-1764)}

La estancia de Álvarez en Roma es posiblemente el aspecto mejor conocido de su biografía. ${ }^{15}$ Llegó el 20 de diciembre de 1758 y fue recibido por el pintor Francisco Preciado de la Vega, recién nombrado director de pensionados. Comenzó a ejercitarse dibujando en el palacio Farnese, el Campidoglio, el Vaticano y diversas iglesias romanas, así como en la Scuola del Nudo (ilustración 3). Incluso acudió en 1764 a dibujar a las Estancias de Rafael, recién abiertas tras años de restauración. Participó en alguno de los concursos que se organizaron para jóvenes artistas, como el de la Academia de Parma en 1762, aunque no obtuvo ningún premio. ${ }^{16}$ También sabe-

15. Cruz AlCaÑIZ, C., «Entre la fortuna...», págs. 55-59; SuredA, J., «Sobre el viaje a Roma...»; Matilla RodríGuez, J.M. (ed.); Zolle, L., Roma en el bolsillo. Cuadernos de dibujo y aprendizaje artístico en el siglo XVIII. Madrid: Museo Nacional del Prado, 2013, págs. 73-79; URREA FernáNDEZ, J., Relaciones artísticas..., pág. 182.

16. ARABASF, Libro de actas, 1757-1769, leg. 3-82, fols. 150v-152v. 


\begin{tabular}{|c|c|c|}
\hline $\begin{array}{l}\text { AÑo DE } \\
\text { ENVÍo }\end{array}$ & OBras ENVIADAS POR DoMingo Álvarez & $\begin{array}{l}\text { ACTA DE LA } \\
\text { REAL ACADEMIA } \\
\text { EN QUE FIGURA }\end{array}$ \\
\hline 1760 & $\begin{array}{l}\text { Júpiter y Juno (original de Annibale Carracci, en Palacio Farnese) } \\
\text { Mercurio y Paris (original de Annibale Carracci, en Palacio Farnese) } \\
\text { Flora Capitolina (original romano, en Palacio Capitolino) } \\
\text { Antínoo Capitolino (original romano, en Palacio Capitolino) } \\
\text { Zenón (original romano, en Palacio Capitolino) } \\
\text { Amor y Psique (original romano, en Palacio Capitolino) } \\
\text { Dos docenas de Academias }\end{array}$ & 8 de abril de 1760 \\
\hline 1761 & El rapto de las sabinas (original de Pietro Cortona, Palacio Capitolino) & 9 de agosto de 1761 \\
\hline \multirow[t]{2}{*}{1763} & $\begin{array}{l}\text { San Gregorio (original de Annibale Carracci, en San Gregorio al Celio) } \\
\text { Tarquinio y Lucrecia (diseño propio) } \\
\text { Cuatro academias }\end{array}$ & 6 de marzo de 1763 \\
\hline & San Miguel (original de Guido Reni, en iglesia de los Capuchinos) & $\begin{array}{l}4 \text { de septiembre } \\
\text { de } 1763\end{array}$ \\
\hline 1764 & $\begin{array}{l}\text { Martirio de san Esteban (original de Pietro de Cortona, en San Lorenzo } \\
\text { de Miranda) }\end{array}$ & \\
\hline 1765 & Tres academias & 5 de mayo de 1765 \\
\hline
\end{tabular}

4. Listado de obras de Domingo Álvarez Enciso remitidas a Madrid según las actas de la Real Academia de Bellas Artes de San Fernando.

mos que plasmaba muchos de esos dibujos en un cuaderno de dibujo o taccuino, y que a partir de ellos iba pintando lienzos, que fue enviando periódicamente a la Academia de Bellas Artes de San Fernando de Madrid (ilustración 4). Y es posible que visitara los talleres de los grandes pintores romanos, como Mengs, Batoni o Corvi. ${ }^{17}$

Por otro lado, son bien conocidos los problemas de disciplina de Álvarez durante la época de su pensión, ya que se gastaba el dinero en vestir con elegancia, elegía por sí mismo las obras que quería dibujar, en vez de seguir los consejos de Preciado, y mantenía una relación amorosa a pesar de que esto estaba terminantemente prohibido en los estatutos de los pensionados. ${ }^{18}$

Además, Preciado cita otro aspecto de su indisciplina que contiene la clave de gran parte de la actividad posterior de Álvarez: junto con el pintoresco relato de sus aventuras amorosas, Preciado también se quejaba de «que como todos quieren vestirse más de aquello a lo que alcanza su pensión, hacen obras unos a escondidas y otros públicamente sin acordarse de que les está prohibido» ${ }^{19}$ En efecto, todo indica que Domingo vendía a particulares las obras que realizaba durante su pensión: es llamativo que el número de obras remitidas a la Academia por Domingo iba siendo cada vez menor cuanto más tiempo pasaba en la ciudad, y las que enviaba debían de ser las de peor calidad, porque la Academia se quejaba de que no apreciaba en él ningún avance. ${ }^{20}$ De hecho, en la última remesa para la Academia, Domingo mandó solo tres academias, y ni un solo lienzo. ${ }^{21}$ Por lo tanto, ya en esta primera estancia Álvarez debió de descubrir las posibilidades que ofrecía Roma para la venta de copias de las grandes pinturas de la ciudad.

17. Gallego, R., «Francisco de Goya: vivir en Roma», en SuredA, J. (coord.), Goya e Italia..., vol. 2, págs. 45-6o, en concreto pág. 47. Queremos agradecer a Raquel Gallego sus orientaciones para la búsqueda de bibliografía y documentación en los archivos y bibliotecas de la ciudad de Roma.

18. CRuz AlCAÑIZ, C., «Entre la fortuna...», págs. 61-64; SUREDA, J., «Sobre el viaje a Roma...»; ConTENTO MÁRQUEZ, R., Formación del buen gusto..., pág. 27; GARCía SÁNCHEZ, J., La Italia de la Ilustración. Madrid: Nowtilus, 2014, pág. 97; URREA FernándeZ, J., Relaciones artísticas..., págs. 133 y 182; Matilla RodríGUeZ, J.M.; Zolle, L., Roma en el bolsillo..., pág. 16; BeDAT, C., La Real Academia de Bellas Artes de San Fernando (1744-1808). Madrid: Fundación Universitaria Española - Real Academia de Bellas Artes de San Fernando, 1989, págs. 259-263; GARCÍA SánCHEZ, J., «Pintores españoles del Grand Tour», en Rodríguez G. De Ceballos, A. (coord.), Francisco Preciado de la Vega. Un pintor español del siglo XVIII en Roma. Madrid: Real Academia de Bellas Artes de San Fernando, 2009, pág. 35.

19. ARABASF, Libro de actas, 1757-1769, leg. 3-82, fol. 141v.

20. Ibidem, fol. 256r. Sureda supone que debía vender incluso las obras que había prometido a la Academia, como un San Miguel Arcángel copiado de Guido Reni, excusándose luego con la institución por no enviarlo diciendo que se le había roto; SUREDA, J., «Sobre el viaje a Roma...».

21. ARABASF, Libro de actas, 1757-1769, leg. 3-82, fol. 301 . 


\section{SEgunda ESTANCIA EN MADRID (1765-1767)}

Al acabar el tiempo de su pensión, Domingo embarcó desde Roma con el también pensionado Mariano Salvador Maella. ${ }^{22}$ Sin embargo, mostrando nuevamente su independencia, se separó de Maella —quien llegó a Madrid tres meses antes que él—y aprovechó el trayecto para visitar diversas localidades. En su expediente matrimonial aseguraba que en los últimos tiempos había visitado:

Siracusa, Barcelona, Monpilier, Genova, Porto Spezia, Pisa, Livorno, parte per mare e parte per terra, ed altre cittá, tannto della Spagna che Genovesato, senza essersi trattenuto piú di uno o due mesi per ciaschedun luogo. ${ }^{23}$

En Barcelona encontró el barco con los cajones de los pensionados, enviados el 27 de febrero desde Roma, y escribió a Preciado que haría con ellos el viaje hasta Madrid. ${ }^{24}$ Allí debió de buscar una colocación, para lo cual recurrió al ya citado Mengs, a quien conocía de su estancia en Roma. ${ }^{25}$ Mengs lo tomó bajo su protección y le consiguió un encargo en un destino que Álvarez ya conocía: la Real Fábrica de Tapices. En 1765 Álvarez se encontraba ya trabajando en ese destino. ${ }^{26}$

Simultáneamente, igual que el resto de sus compañeros, solicitó el nombramiento como académico de la Real Academia de Bellas Artes de San Fernando. La Academia contestó el 14 de diciembre de 1766 otorgándoselo, pero no como académico de mérito, que era el que había concedido a sus compañeros pensionados, ${ }^{27}$ sino como supernumerario, un título que se aplicaba a artistas que aún estaban en formación y no podían optar a puestos como el de profesor en la Academia. ${ }^{28}$ De este modo, la posibilidad de progresar como profesor en la Real Academia quedaba cerrada para Álvarez.

\section{SEgunda ESTANCIA EN RoMa (1767-1768)}

En julio de 1767 Álvarez viajó de nuevo a Roma, donde comenzó de inmediato las diligencias para contraer nupcias. Su futura esposa era Angela Morosini, de veintiséis años, perteneciente a una familia romana, tal vez con vínculos con el mundo artístico ${ }^{29}$ pero no muy pudiente: Domingo indicará que al «matrimonio no trujo la susodicha más bienes que la ropa de su vestir, y yo llevé lo mismo». ${ }^{30}$ Sabemos que en 1767 Angela vivía en una casa contigua al palacio Lante en compañía de su madre, Antonia Raffi, cuatro hermanos y un sobrino, ya que su padre, Ottavio Morosini, había abandonado el hogar familiar (ilustración 5).

22. URREA FERNÁNDEZ, J., Relaciones artísticas..., pág. 182.

23. ASVR, Dossieres matrimoniales, Bernardino Monti, 1767, s/f.

24. García Sánchez, J., «Cartas de Francisco Preciado de la Vega a Manuel de Roda (1765-1779)», Academia. Boletín de la Real Academia de Bellas Artes de San Fernando, 104-105, 2007, pág. 62.

25. Cruz AlcañIZ, C., «Entre la fortuna...», págs. 60 y 61.

26. JoRDÁN DE URRÍES, J., «El clasicismo en los discípulos...», pág. 101.

27. García Sepúlveda, M.P.; Navarrete Martínez, E., Relación general de académicos (1752-2015). Madrid: Real Academia de Bellas Artes de San Fernando, 2016, págs. 109, 118, 264, 265, 376 y 484.

28. ARABASF, Libro de actas, 1757-1769, leg. 3-82, fols. 414r-414v.

29. Debenedetti, E., Artisti e artigiani a Roma, II: dagli stati delle anime del 1700, 1725, 1750, 1775. Roma: Bonsignori, 2005, págs. 199, 253 y 331.

30. Archivo Municipal de Jerez (AMJ), Protocolos notariales, José Álvarez, leg. 2975, 1798-1800, fol. 674v. 


\begin{tabular}{|c|c|c|c|c|}
\hline AÑo & PARROQUIA & Personas QUe VIVÍAN EN LA CASA & $\begin{array}{l}\text { CALLE O } \\
\text { MANZANA }\end{array}$ & $\begin{array}{l}\text { REFERENCIA DE LOS } \\
\text { ESTADOS DE ÁNIMAS }\end{array}$ \\
\hline 1767 & San Eustaquio & $\begin{array}{l}\text { Antonia Raffi moglie reli:ta di Ott }{ }^{\circ} \text { Morosini, } 53 \\
\text { Marianna, } 31 \\
\text { Alessandro, } 27 \\
\text { Giuseppe, } 23 \\
\text { Paolo, } 17 \\
\text { Andrea Ravieri, fil. di Ant }{ }^{\circ} \text { Rom }^{\circ}, 7 \\
\end{array}$ & Isola Lante & $\begin{array}{l}\text { ASV, Stati delle anime, } \\
\text { S. Eustachio, } 1767 \text {, fol. } 73 \text { r. }\end{array}$ \\
\hline 1768 & San Eustaquio & $\begin{array}{l}\text { Sig. Domenico Alvares figlio q }{ }^{\circ} \text { Giovanni Antonio Burgens } \\
\text { Diec: in Spagna, } 30 \\
\text { Sigra. Angela Morosini, moglie, figlia di Ottavio, romana, } 26 \\
\text { Paolo Morosini germano di Angela, } 18 \\
\text { Antonia Raffi, figlia di Francesco, moglie di Ottavio Morosini } \\
\text { e madre di Angela, } 54\end{array}$ & Isola Lante & $\begin{array}{l}\text { ASV, Stati delle anime, } \\
\text { S. Eustachio, } 1768 \text {, fol. } 73 \text { r. }\end{array}$ \\
\hline 1774 & $\begin{array}{l}\text { San Lorenzo } \\
\text { in Lucina }\end{array}$ & $\begin{array}{l}\text { Dom }^{\text {co }} \text { Alvarez, pitte } \\
\text { Angela Morosini mug } \\
\text { Camilo figlio an. } 9\end{array}$ & $\begin{array}{l}\text { Seguito Ssmo. } \\
\text { verso Strada } \\
\text { Vittoria }\end{array}$ & $\begin{array}{l}\text { ASV, Stati delle anime, } \\
\text { S. Lorenzo in Lucina, 1774, } \\
\text { fol. } 46 \mathrm{r} \text {. }\end{array}$ \\
\hline 1775 & $\begin{array}{l}\text { San Lorenzo } \\
\text { in Lucina }\end{array}$ & $\begin{array}{l}\text { Dom }^{\text {co }} \text { Alvarez, pitt } \\
\text { Angela Morosini mug } \\
\text { Camillo figlio an. } 10\end{array}$ & $\begin{array}{l}\text { Strada } \\
\text { della Croce }\end{array}$ & $\begin{array}{l}\text { ASV, Stati delle anime, } \\
\text { S. Lorenzo in Lucina, 1775, } \\
\text { fol. } 45 \mathrm{v} \text {. }\end{array}$ \\
\hline 1776 & $\begin{array}{l}\text { San Lorenzo } \\
\text { in Lucina }\end{array}$ & $\begin{array}{l}\text { Dom }^{\mathrm{co}} \text { Alvarez, pitte } \\
\text { Angela Morosini mog } \\
\text { Camillo figlio an. } 11\end{array}$ & $\begin{array}{l}\text { Strada } \\
\text { della Croce }\end{array}$ & $\begin{array}{l}\text { ASV, Stati delle anime, } \\
\text { S. Lorenzo in Lucina, 1776, } \\
\text { fol. } 46 \mathrm{r} \text {. }\end{array}$ \\
\hline 1777 & $\begin{array}{l}\text { San Lorenzo } \\
\text { in Lucina }\end{array}$ & $\begin{array}{l}\text { Domenico Alvarez, pitte } \\
\text { Angela Morosini mog } \\
\text { Camillo figo an. } 12\end{array}$ & $\begin{array}{l}\text { Strada } \\
\text { della Croce }\end{array}$ & $\begin{array}{l}\text { SV, Stati delle anime, } \\
\text { S. Lorenzo in Lucina, 1777, } \\
\text { fol. } 43 \mathrm{r} \text {. }\end{array}$ \\
\hline 1778 & $\begin{array}{l}\text { San Lorenzo } \\
\text { in Lucina }\end{array}$ & $\begin{array}{l}\text { Dom }^{\circ} \text { Alvarez, pitt } \\
\text { Angela Morosini m } \\
\text { Camillo fo an. } 12 \\
\end{array}$ & Strada Paolina & $\begin{array}{l}\text { ASV, Stati delle anime, } \\
\text { S. Lorenzo in Lucina, 1778, } \\
\text { fol. } 34 \text { r. }\end{array}$ \\
\hline 1788 & $\begin{array}{l}\text { San Lorenzo } \\
\text { in Lucina }\end{array}$ & $\begin{array}{l}\text { Dom }^{\text {co }} \text { Albz pitt } \\
\text { Angela Morosini mug } \\
\text { Camillo figo di an. 22 Faleg }\end{array}$ & Strada Paolina & $\begin{array}{l}\text { ASV, Stati delle anime, } \\
\text { S. Lorenzo in Lucina, 1788, } \\
\text { fol. } 32 \mathrm{v} \text {. }\end{array}$ \\
\hline
\end{tabular}

5. Listado de residencias de Domingo Álvarez Enciso en Roma según los datos del Archivio Storico del Vicariato di Roma.

Para poder casarse, Domingo debía aportar dos testigos que acreditaran que no tenía un matrimonio previo. En un principio solicitó una exención, pero al ver que ese trámite se alargaba en el tiempo, presentó a dos pintores españoles, pensionados en esos momentos en Roma y ambos del entorno de Mengs: Alejandro de la Cruz y Severo Asensio. ${ }^{31}$ Finalmente, gracias a la declaración de estos, Domingo pudo casarse el 27 de septiembre de 1767 en la parroquia de Sant'Eustaquio. ${ }^{32}$ Apenas un año después toda la familia abandonó el domicilio de Isola Lante.

¿Por qué tenía Domingo tanta prisa por casarse? En 1774, cuando Domingo regresó de nuevo a Roma, vivía con Angela y con un hijo, Camillo, que en esos momentos tenía nueve años. ${ }^{33}$ Según este dato, Camillo habría nacido en 1765, es decir, antes del matrimonio de Domingo y Angela. Por lo tanto, parece que Domingo abandonó Roma cuando Angela esperaba ya un hijo suyo y que, tras lograr una colocación en Madrid, regresó a Roma para contraer matrimonio con ella.

Sobre este hijo sabemos que vivió con sus padres al menos hasta 1788, fecha en que Domingo y Ángela abandonaron Roma. Para entonces, Camillo, que era carpintero, tenía veintidós años. No viajó con sus padres a Cádiz, ${ }^{34}$ aunque parece lógico que, con esa edad, permaneciera en Roma desempeñando su oficio. Sin embargo, no tenemos noticias posteriores sobre él, ni siquiera referencias en la correspondencia de su padre durante los siguientes viajes que hizo a Roma. Y, lo que es más desconcertante, cuando Domingo hizo testamento, en 1800, indicó expresamente, al hablar de su matrimonio: «del qual no he tenido hijos algunos, lo declaro así para que conste». ${ }^{35}$ Lo más probable es que Camillo hubiera fallecido y Domingo quisiera indicar que no le quedaba ningún hijo que pudiera heredar.

31. ASVR, Rubricella matrimoniarum, Bernardo Monti, 1766-1767, fols. 596r-597v.

32. ASVR, Matrimoni, Sant'Eustachio, 1665-1784, fol. 309v; GALLEGo, R., «Sobre las capitulaciones matrimoniales de Francisco de Goya y la prisa del aragonés en abandonar Roma», Archivo Español de Arte, vol. 87, 346, 2014 , pág. 117.

33. ASVR, Stati delle anime, San Lorenzo in Lucina, 1775, fol. $46 \mathrm{r}$

34. ARABASF, Secretario general. Enseñanza. Escuelas de dibujo. Cádiz, 1769-1838, leg. 2-38-28, s/f.

35. AMJ, Protocolos notariales, José Álvarez, leg. 2975, 1798-180o, fols. 673r-676v. 
En 1768 Álvarez vovió a abandonar Roma para regresar a Madrid. Nada más llegar se incorporó al trabajo que Mengs le había conseguido para pintar unas sobrepuertas en el Palacio Real ${ }^{36}$ y para trabajar en la Fábrica de Tapices. ${ }^{37}$ Sin embargo, pocos meses después de la llegada de Álvarez, Mengs marchó a su vez a Roma, y Domingo, que no debía de estar contratado de forma directa sino al servicio de Mengs, perdió su trabajo en el Palacio Real. En esas circunstancias, Domingo regresó al taller de Andrés de la Calleja, aunque la insuficiencia de encargos hizo que tuviera que vivir de la ayuda de sus tíos Agustín y Manuel Sáinz Alfaro. ${ }^{38}$

Sin el apoyo de Mengs y dependiente económicamente de sus tíos, Domingo decidió regresar a Roma. Es posible que hubiera tomado esta decisión ya en 1769, cuando Mengs abandonó Madrid. Ese año, su primo Fernando escribió a su tío Pedro, asentado en México, preguntando si recordaba que tuvieran algún pariente en Roma. Pedro hizo memoria de un exjesuita pariente de la familia, José de Nájera Enciso, y recomendó a Fernando que le escribiera. ${ }^{39}$ Podemos suponer que la pregunta provenía de Domingo - no será la única vez que Fernando escriba una carta a petición de Domingo-,$^{40}$ quien deseaba encontrar apoyos familiares en la Ciudad Eterna. No obstante, el viaje acabó por posponerse hasta 1773.

\section{TERCERA ESTANCia en Roma (1773-1788)}

Nada más llegar a Roma hacia marzo de 1773, Domingo hizo lo posible por entrar a formar parte del ambiente artístico de la ciudad. En primer lugar, se inscribió en el concurso Balestra, organizado por la Accademia di San Luca. ${ }^{41}$ No obtuvo ningún premio, pero en cualquier caso el hecho de participar le permitió volver a integrarse en el grupo de artistas de la capital.

En segundo lugar, es significativo el sitio en el que se instaló para vivir: el vecindario de San Lorenzo in Lucina, en los aledaños de plaza Spagna. Este espacio le situaba en las inmediaciones de los talleres de artistas de prestigio, como Pompeo Batoni y Domenico Corvi — también vecinos de San Lorenzo in Lucina, parroquia a la que también pertenecieron Mengs y su cuñado, Von Maron.$-{ }^{42}$ Se sabe que los talleres de estos grandes pintores eran un lugar de vi-

36. Jordán de UrRíEs, J., «El clasicismo en los discípulos españoles de Mengs», en Negrete Plano, A. (ed.), Anton Raphael Mengs y la Antigüedad. Madrid: Real Academia de Bellas Artes de San Fernando - Fundación Mapfre, 2013 , pág. 97.

37. Archivo General de Simancas (AGS), Estado, leg. 4999, carta de Manuel Sáinz Alfaro, 31 de diciembre de 1785, s/f.; CRUZ AlCAÑIZ, C., «Entre la fortuna...», págs. 60 y 61; JoRDÁN DE URRÍES, J., «"Crear artífizes yluminados en el buen camino de el Arte": los últimos discípulos españoles de Mengs», Goya, 340, 2012, pág. 215; idem, «Los últimos discípulos españoles de Mengs: Ramos, Agustín, Salesa, Napoli y Espinosa», en I Congreso Internacional Pintura española siglo XVIII, 1998, pág. 439; idem, «El clasicismo en los discípulos...», pág. 101.

38. Cruz AlcaÑIz, C., «Entre la fortuna...», págs. 60 y 61.

39. Universidad de Texas - Centro Dolph Briscoe de Historia Americana, carta de Pedro Álvarez Enciso a Fernando Álvarez Enciso, 6 de marzo de 1769, fol. 2r.

40. ARABASF, Secretario general. Académicos de mérito y académicos supernumerarios por la Pintura, 1754-1795, leg. 5-174-1, s/f.

41. Cipriani, A.; Valeriani, E., I disegni di figura nell'Archivio Storico dell'Accademia di San Luca. Roma: Accademia Nazionale di San Luca, 1991, vol. III, pág. 96; CánovAs del CAstıllo, S., «Artistas españoles en la Academia de San Luca de Roma», Academia. Boletín de la Real Academia de Bellas Artes de San Fernando, 68, 1989, pág. 174.

42. Véase, por ejemplo, ASVR, Stati delle anime, San Lorenzo in Lucina, 1773, fol. 35v (Domenico Corvi) y $60 v$. (Pompeo Batoni). Véase también GALLEGo, R., «Artistas y lugares en Roma hacia 1770», en SuREDA, J. (coord.), Goya e Italia..., vol. 1, págs. 245-247, en concreto pág. 245; MICHEL, O., Vivre et peindre à Rome au XVIII siècle. Roma: École Française de Rome, 
sita casi obligada para los viajeros del Grand Tour, quienes solían encargar obras a estos artistas. Y no es descabellado pensar que otros artistas, con menos prestigio, se beneficiarían también de las visitas y encargos de algunos visitantes menos pudientes.

Así, Domingo comenzó a realizar copias de diversas pinturas de Roma que iba vendiendo a particulares, tal y como había hecho - entonces ilegalmente- en su primera estancia romana. Copiaba obras de Mengs, de Maratta y, sobre todo, de Rafael, adquiriendo un gran prestigio por sus copias de las Estancias, hechas en pequeño tamaño para facilitar su venta y traslado. ${ }^{43}$

Aun así, Domingo continuó buscando el apoyo de otras personalidades con prestigio en Roma: siguió en contacto con Mengs y, a pesar de rondar los cuarenta años, asistió como alumno a las clases de natural que impartía este pintor; mantuvo también el contacto con Preciado de la Vega, al que llegó a retratar; ${ }^{44} \mathrm{y}$ formó parte del círculo de los ministros Azara y Grimaldi, que procuraron favorecerle por su estrecha relación con Mengs. ${ }^{45}$

Otro apoyo, como ya lo había sido a lo largo de toda su vida, fue su familia, en algunos casos por un azar del destino: Álvarez contaba en su testamento que la mayor parte del dinero que poseía lo había logrado por la herencia de un tío suyo, Manuel Alejano, que vivía en Madrid. ${ }^{46}$

En otros casos, en cambio, el apoyo familiar fue más consciente. En enero de 1785, pocos días después del fallecimiento de su antiguo maestro, Andrés de la Calleja, Domingo envió un memorial a la Real Academia a través de su tío Agustín Sáenz de Alfaro. Tal vez pensó que el memorial sería mejor acogido si llegaba firmado por su tío, cuyo prestigio en la corte seguía vigente. En el memorial, Álvarez hacía valer sus méritos para solicitar a la Academia dos posibles puestos: uno como sustituto del citado Calleja en la Real Academia de Madrid, y otro como sustituto en Roma de Preciado de la Vega «en sus ausencias y enfermedades». ${ }^{47}$ Como se ve, parece que lograr un puesto como profesor que le proporcionara más estabilidad seguía siendo la esperanza de Álvarez. La Academia, antes de responder a la petición, solicitó diferentes opiniones, incluidas la de Ana María Mengs y la de Eugenio Llaguno, quienes remarcaron la habilidad de Álvarez para copiar las obras de Rafael.$^{48} \mathrm{El} \mathrm{rey} \mathrm{decidió} \mathrm{encargar} \mathrm{a} \mathrm{Álvarez} \mathrm{que} \mathrm{fuera} \mathrm{envian-}$ do a Madrid copias de las Estancias destinadas a la Academia (ilustración 6). ${ }^{49}$ De este modo, Domingo tuvo que resignarse nuevamente a no lograr el ansiado puesto como profesor y seguir viviendo como copista en Roma.

1996, págs. 44-46; GARCÍA SÁNCHEZ, J., «Vida, obra, mecenazgo y clientela de los artistas españoles en la Roma del siglo XVIII», Boletín del Museo e Instituto Camón Aznar, 100, 2007, pág. 55.

43. TellecheA Idígoras, J.I., «Cartas inéditas de Manuel Salvador Carmona a Eugenio Llaguno Amírola (1780-1781)», Academia. Boletín de la Real Academia de Bellas Artes de San Fernando, 28, 1969, pág. 59; Matilla RodríGuez, J.M.; Zolle, L., Roma en el bolsillo..., pág. 79; JoRDÁN DE URRíEs, J., «Los últimos discípulos...», pág. 442; idem, «"Crear artífizes yluminados..."», pág. 215.

44. Cruz Alcañiz, C., «Entre la fortuna...», págs. 65-67.

45. Jordán de Urríes dice que si Álvarez logró sobrevivir en Roma fue gracias al apoyo de Azara y de Grimaldi; JoRDÁN DE URRíEs, J., «Los últimos discípulos...», pág. 442.

46. Tenemos constancia de un Manuel Alejano, abogado en Madrid en la década de 1780, aunque no la seguridad de que se trate del tío de Domingo, al no haber encontrado más datos sobre su vida; Astorgano ABAJo, A., «Biografía de Sal-

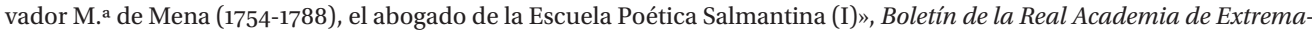
dura de las Letras y las Artes, 24, 2016, pág. 127.

47. Cruz AlcaÑIZ, C., «Entre la fortuna...», pág. 66.

48. AGS, Estado, leg. 4999, carta de Eugenio Llaguno y Amírola, s/f.; JoRDÁN DE URRÍES, J., «“Crear artífizes yluminados..."», pág. 215; idem, «Los últimos discípulos...», pág. 442.

49. ARABASF, Secretario general. Académicos por la Sección de Pintura, 1747-1856, leg. 1-49-4, s/f; CRUZ ALCAÑIZ, C., «Entre la fortuna...», págs. 66 y 67; JoRDÁN DE URRíEs, J., «Los últimos discípulos...», págs. 442 y 443; idem, «"Crear artífizes yluminados...”», pág. 215; GARCÍA SÁNCHEZ, J., «Vida, obra, mecenazgo...», pág. 55. 
6. Domingo

Álvarez Enciso

Escuela de Atenas

(copia de Rafael),

c. 1786-1787, óleo

sobre lienzo,

$62 \times 88 \mathrm{~cm}$. Real

Academia

de Bellas Artes

de San Fernando, Madrid.

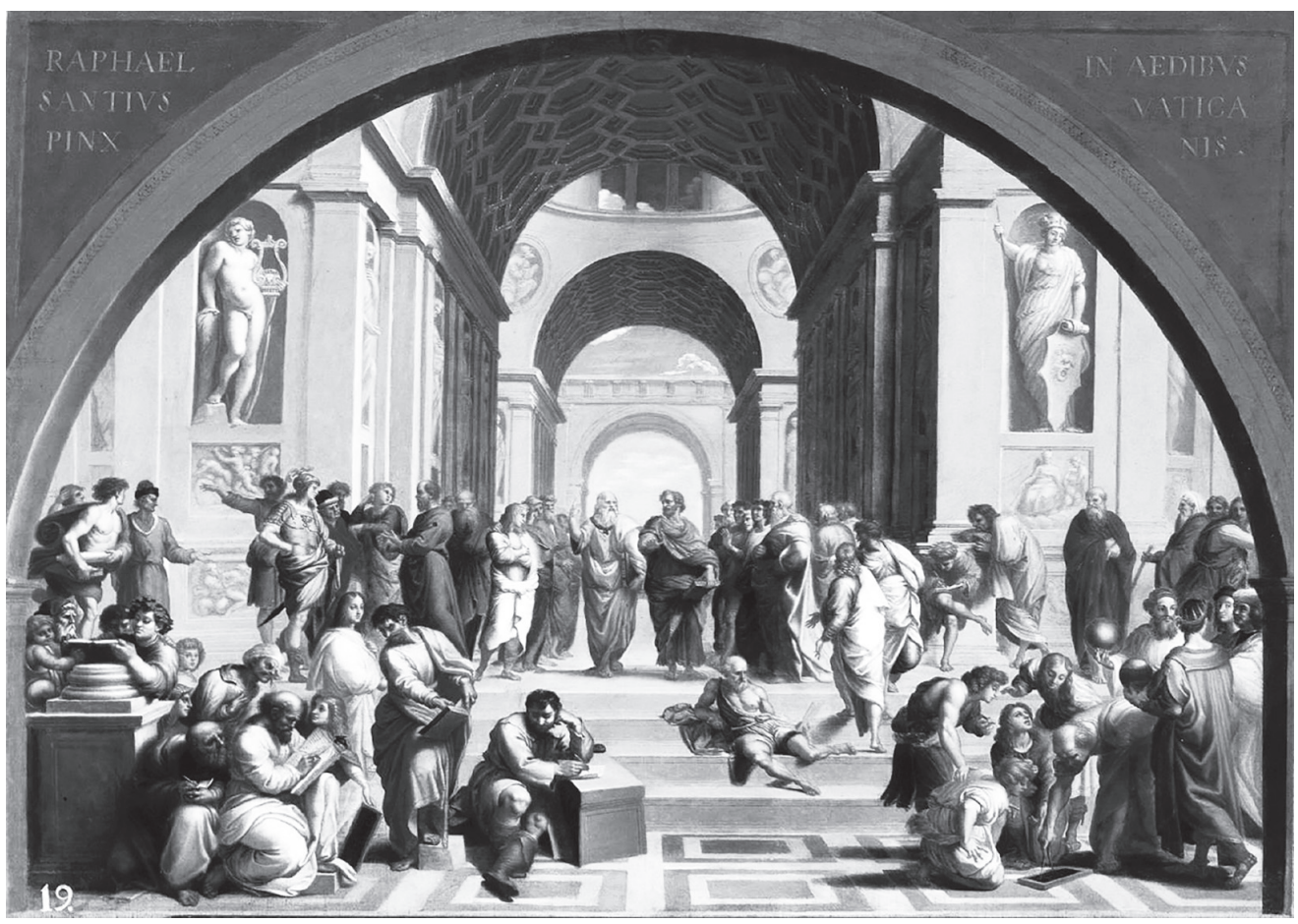

Estancia en CÁdiz y últimos viajes a Roma (1788-1800)

En 1787 Azara recibió una solicitud de la ciudad de Cádiz unas esculturas de yeso para la Escuela de Dibujo que se iba a poner en marcha en esa ciudad. ${ }^{50}$ No sabemos si Domingo Álvarez se enteró de esta gestión y solicitó su ayuda o si la iniciativa partió del propio Azara. El hecho es que, además de enviar los yesos, Azara propuso a los comitentes que contrataran a Domingo como director de pintura de la futura escuela. En Cádiz consultaron a la Real Academia de Bellas Artes de San Fernando y dieron una respuesta positiva, al tiempo que pidieron a Azara que realizara el contrato de Álvarez en su nombre. ${ }^{51}$ Por fin, Domingo tenía el ansiado puesto como profesor en una escuela artística.

En 1788 Domingo llegó a Cádiz con su mujer, y comenzó la docencia en la escuela al año siguiente. Su labor era dirigir la sala de pintura, para lo cual contaba con hasta cuatro asistentes. Además, su sueldo duplicaba el de los profesores de arquitectura y escultura, y por su mayor prestigio y edad ejercía una cierta supervisión sobre estos..$^{52}$ También realizaba pinturas - sobre

50. Archivo de la Real Academia Provincial de Bellas Artes de Cádiz (ARABAC), Cuentas generales de la Academia, libro I, 1787-1789, 26 de diciembre de 1787. Queremos dar las gracias a Rosario Martínez y a José María Collantes por habernos facilitado la transcripción de los documentos de este archivo.

51. ARABASF, Secretario general. Enseñanza. Escuelas de dibujo. Cádiz, 1769-1838, leg. 2-38-28, s/f; Secretario general. Académicos por la Sección de Pintura, 1747-1856, leg. 1-49-4, s/f; Archivo Histórico de Cádiz (AHCA), Fondo Pettenghi, Escuela de Nobles Artes, leg. 35650, exp. 54, contrato de Domingo Álvarez como director de dibujo de la escuela, 19 de julio de 1788; ARABAC, Cuentas generales de la Academia, libro I, 1787-1789.

52. Orozco Acuaviva, A., Orígenes de la Academia de Nobles Artes de Cádiz y artistas de su tiempo. Cádiz: Ateneo de Cádiz, 1973, pág. 9; Gascón Heredia, M.T., Estudio histórico de la Escuela de Nobles Artes de Cádiz. 1789-1842. Cádiz: Real Academia de Bellas Artes de Cádiz, 1989, págs. 36-38; BANDA Y VARGAS, A. DE LA, «La pintura gaditana del Academicismo al Romanticismo», en Antón Solé, P. (dir.), Enciclopedia gráfica gaditana, 5 vols. Cádiz: Caja de Ahorros de Cádiz, 1984-1988, vol. 4, fasc. VII, págs. 101-102. 
todo de carácter religioso - para las empresas artísticas que se impulsaban en la ciudad. ${ }^{53}$ Estos años fueron también los de su consagración artística: en 1794 consiguió por fin el nombramiento como académico de mérito de la Academia de Bellas Artes de San Fernando ${ }^{54}$ y, en 1795, el de pintor de cámara del rey ${ }^{55}$ Es interesante señalar que en ambos casos volvió a tener un papel muy importante su familia: la instancia para académico de mérito fue remitida por su ya citado primo Fernando, tal vez para beneficiarse de su reputación en los Cinco Gremios Mayores de Madrid; ${ }^{56}$ y el nombramiento como pintor de cámara se le concedió no por su mérito, que según Bayeu era «regular», sino porque «su tío D[o]n Manuel Sainz de Alfaro sirvió de Ayuda de la R[ea]l Furriera». ${ }^{57}$

Asimismo, Domingo debió de estar en contacto con las élites ilustradas de Cádiz, como revela una pequeña anécdota. Un personaje destacado en la ciudad era Sebastián Martínez, comerciante y célebre coleccionista de arte, oriundo, como Álvarez, de un pequeño pueblo de la sierra riojana.$^{58}$ En 1789 Martínez recibió desde Roma varias estampas que reproducían las Estancias de Rafael. Sin embargo, el inquisidor de la ciudad, Pedro Manuel Sánchez Bernal, se enteró de que algunas de ellas representaban «diferentes figuras de hombres y mujeres enteramente desnudos». Para que un perito determinara la decencia de las mismas, solicitó el criterio de Álvarez. Este, sin entrar en el juego,

formó el juicio que teniéndolas Su Santidad en su mismo palacio y comprándolas en Roma todos los Príncipes Christianos para llevarlas a sus Cortes, por consiguiente, pueden traerse a esta ciudad y tenerse por qualquiera persona en su casa. ${ }^{59}$

Por lo tanto, Álvarez entró pronto a formar parte del entorno artístico e ilustrado de Cádiz. Aun así, los años pasados en Roma le habían convertido casi en un extranjero en España, por lo que incluso en Cádiz parece que mantuvo especialmente contacto con la comunidad italiana de la zona. Es sintomático que en su testamento, redactado en 1800, Álvarez cite solo a tres personas de su entorno, de las que dos eran italianas: su criada, Catalina Berruti, y un amigo pintor, Juan Santiago Cerruti. ${ }^{60}$

Tal vez por esa nostalgia italiana, Álvarez se ofreció en varias ocasiones para viajar a Italia con la finalidad de cumplir encargos de la escuela. El primer viaje tuvo lugar en agosto de 1791, sin que sepamos más sobre sus actividades en la ciudad. ${ }^{61}$ Más conocido es el segundo viaje, el cual realizó entre agosto de 1795 y agosto de $1796 .{ }^{62}$ El pintor viajó acompañado de su esposa

53. Alonso de la Sierra, J.; Alonso de la Sierra, L., Cádiz: guía artística y monumental. Cádiz: Sílex, 2006, pág. 80. 54. ARABASF, Libro de actas, 1795-1802, leg. 3-86, fol. 2r.

55. Cruz Alcañiz, C., «Entre la fortuna...», pág. 70; Contento MárQueZ, R., Formación del buen gusto..., pág. 32.

56. ARABASF, Secretario general. Académicos de mérito y académicos supernumerarios por la Pintura, 1754-1795, leg. 5-174-1, s/f.

57. CRuz AlCAÑIZ, C., «Entre la fortuna...», pág. 70.

58. Pemán Medina, M., «Don Sebastián Martínez, amigo de Goya», en El arte del siglo XIX. II Congreso Español de Historia del Arte, 11-14 de diciembre de 1978, Valladolid. Valladolid: Comité Español de Historia del Arte, vol. 1, págs. 141-143; Gil-Díez Usandizaga, I., «Sebastián Martínez, el amigo de Goya», Brocar. Cuadernos de Investigación Histórica, 38, 2014, págs. 197-209.

59. GACTO FERnÁNDEZ, E., «El arte vigilado (sobre la censura estética de la Inquisición española en el siglo XVIII)», Revista de la Inquisición, 9, 2000, pág. 45.

6o. AMJ, Protocolos notariales, José Álvarez, leg. 2975, 1798-180o, fols. 674v-675r.

61. En septiembre de 1791 se indicó en las cuentas de la escuela: «En esta relación no se incluye el sueldo de D. Domingo Álvarez por hallarse ausente con licencia en Italia, para cuyo destino salió de esta ciudad el día 8 del mes po pas $^{\text {do }}$. de agosto"; ARABAC, Comprobantes de Arcas, libro I, 1790-1791, 26 de septiembre de 1791, hoja 3.

62. JoRDÁn DE URRÍES, J., «“Crear artífizes yluminados...”, pág. 215. De hecho, no se le pagó el sueldo desde julio de 1795 hasta agosto de 1796; ARABAC, Comprobantes de Arcas, libro III, 1794-1795, 27 de agosto de 1795; Comprobantes de Arcas, libro IV, 1796-1797, septiembre de 1796, hoja 9. 


\begin{tabular}{ll} 
OBRAS & TEMAS / AUTORES \\
\hline I escultura grande & Hércules Farnesio, por Carlo Albacini \\
\hline & Baco \\
5 esculturas medianas & Amor y Psiquis \\
& Sacha \\
& Discóbolo de Juno \\
\hline I I dibujos de cabezas & Marco Benefiali \\
& Andrea Sacchi \\
& Carlo Maratta \\
& Guido Reni \\
& 3 sin autor \\
& 4 de Buenaventura Salesa \\
& 2 de Carlos Espinosa \\
& I de Corrado Giaquinto \\
& I de Antonio Vighi \\
& I de autor no conocido copiando a Mengs \\
& I de Giuseppe Cades \\
& I de Franz Caucig \\
& I de Vinenzo Camuccini \\
& 2 de Teodoro Matteini \\
& I de Stefano Tofanelli \\
& 2 de Domenico Corvi \\
& 2 de Pompeo Batoni \\
\hline &
\end{tabular}

y ambos se instalaron en su antigua calle, della Croce. ${ }^{63}$ Su encargo era conseguir yesos y dibujos que facilitaran la formación de los estudiantes de la escuela (ilustración 7). ${ }^{64}$

Las gestiones que realizó esos meses nos muestran los vínculos y contactos que aún tenía en Roma y que fundamentalmente están ligados a los dos artistas con los que más contacto tuvo allí: Preciado de la Vega y Mengs: así, Álvarez visitó a Alberico Mengs para comprarle «cinco estatuas medianas»; ${ }^{65}$ al escultor Vincenzo Pacetti, gran amigo de Preciado de la Vega, ${ }^{66}$ para comprar un yeso del Hércules Farnesio ${ }^{67} \mathrm{y}$ dos academias de Batoni; ${ }^{68}$ a sus antiguos condiscípulos Salesa y Espinosa, a los que también pidió academias; ${ }^{69}$ y a Catalina Cherubini, viuda de Preciado de la Vega, para ojear libros y

7. Listado de obras enviadas por Domingo Álvarez Enciso de Roma a Cádiz en 1796. otras pertenencias de su marido que ella estaba vendiendo, aunque al final no compró ninguna. ${ }^{70}$ Además, durante su estancia en Roma Domingo fue propuesto por Giuseppe Cades - también antiguo conocido de Preciado-y otros pintores como académico de San Luca, cuando era director de la misma precisamente Vincenzo Pacetti. ${ }^{71}$

Mientras llevaba a cabo esas gestiones, Domingo se ofreció también para recibir a los cinco pensionados que la escuela de Cádiz mandaba a Roma. Este envío de alumnos debió de ser promovido por él mismo: es sintomático que todos ellos fueran de la sala de pintura, la que él dirigía. Se trataba de cinco jóvenes llamados Manuel Montano, Antonio Font, Antonio Roca, José García y José Ramonet. ${ }^{72}$ Domingo estuvo pendiente de su llegada a Roma, y durante la espera pidió a Azara que los protegiera, el cual prometió «faborezerlos en q[uan]to esté de su parte». ${ }^{73}$ Cuando llegaron, en enero de 1796, Álvarez fue a buscarlos, los alojó en una posada («una osteria bastante infeliz», suspiraba Montano $)^{74}$ y los llevó a conocer a Azara. ${ }^{75}$ Como se acabaron instalando en casas separadas, Domingo, para que no se sintieran aislados, indicaba que «bienen

63. AHCA, Fondo Pettenghi, leg. 35651, exp. 3, carta de Manuel Montano, 6 de julio de 1796.

64. Ibidem, exp. 8, carta de Domingo Álvarez, 29 de diciembre de 1795; $\mathrm{y}$ «Nota de los Dibuxos q $\mathrm{e}^{\mathrm{e}}$ ha traido de Roma $\mathrm{D}^{\mathrm{n}}$ Domingo Albarez para esta Academia de Bellas Artes»; ARABAC, Comprobantes de Arcas, libro IV, 1796-1797, julio de 1796, hojas 5 y 7 ; septiembre de 1796 , hoja 8.

65. AHCA, Fondo Pettenghi, leg. 35651, exp. 8, 6 de abril de 1796.

66. Rodríguez G. De Ceballos, A. (coord..), Francisco Preciado de la Vega..., pág. 83.

67. Cipriani, A. (ed.), Roma 1771-1819. I Giornali di Vincenzo Pacetti. Pozzuoli: Naus, 2011, págs. 162-165; Cruz AlCAÑIZ, C., «Entre la fortuna...», pág. 68.

68. Cipriani, A. (ed.), Roma 1771-1819..., pág. 165. Pacetti anotó en su diario que en realidad le dio una de Pompeo Batoni y otra suya, que Álvarez creyó también de Batoni; véase CRUZ AlCAÑIZ, C., «Entre la fortuna...», pág. 68.

69. AHCA, Fondo Pettenghi, leg. 35651, exp. 8, carta de Domingo Álvarez, 6 de abril de 1796.

70. Ibidem, exp. 3, carta de Manuel Montano, 18 de mayo de 1796.

71. Cipriani, A. (ed.), Roma 1771-1819..., pág. 164; CÁNovas Del Castillo, S., «Artistas españoles...», pág. 174; JoRDáN DE URRíEs, J., «"Crear artífizes yluminados...”», pág. 215.

72. Sobre estos pensionados, GAScón HEREDIA, M.T., Estudio histórico..., págs. 119-122.

73. AHCA, Fondo Pettenghi, leg. 35651, exp. 8, carta de Domingo Álvarez, 29 de diciembre de 1795; y exp. 7, carta de José Nicolás de Azara, 18 de noviembre de 1795.

74. Ibidem, exp. 3, carta de Manuel Montano, 8 de enero de 1796.

75. Ibidem, exp. 7, carta de José Nicolás de Azara, 6 de enero de 1796. 
a mi casa las más noches y yo boi a las suyas y todos juntos bamos los días de fiesta a ver lo mejor de Roma». ${ }^{76}$ Sería interesante saber qué consideraba Domingo «lo mejor de Roma», pero la correspondencia de los pensionados no da muchas pistas: Montano solo indica que cuando llegaron a la ciudad Domingo les llevó a visitar San Pedro, y Font, más prosaico, solo cita «la merienda en la hosteria de Sta. Maria in Trastiber donde hay el vino bueno». ${ }^{77}$ Por último, Álvarez intentó que mantuvieran los vínculos que él ya tenía en Roma: por ejemplo, llevó a Montano a conocer a Catalina Cherubini y le animó a visitarla con frecuencia, lo que este cumplió. ${ }^{78}$

Además, mientras estuvo en Roma, Álvarez fue orientando su aprendizaje. Y, curiosamente, los consejos que les dio recuerdan mucho a su formación artística: les envió a dibujar al Campidoglio y al Vaticano, donde copiaron algunas de las mismas obras que había copiado Álvarez en su juventud, incluidas las Estancias del Vaticano, ${ }^{79}$ aunque Domingo también propuso modelos más «barrocos», como el Anima beata de Bernini, que mandó dibujar a Montano. ${ }^{80}$ Álvarez supervisaba las obras que realizaban: según Montano, «dicho señor D[o]n Domingo no se descuida en venir a ver lo que trabajamos»; ; y en otra ocasión llevó los dibujos realizados «a mostrárselos a nuestro Excelentísimo Señor, el q[u]e con mucho amor y pasiencia fue mirando una por una y dándonos de ellas su sabio parecer». ${ }^{82}$ Finalmente, viendo tal vez la dificultad de estos jóvenes para formarse sin un director, propuso al pintor Stefano Toffanelli para que guiara su aprendizaje. ${ }^{83}$

En 1796 Álvarez se hallaba ya de vuelta en Cádiz, aunque su estancia estaba destinada a ser breve. En septiembre de 1800 se originó en Cádiz la primera gran epidemia de fiebre amarilla que conoció la ciudad. ${ }^{84}$ Domingo y su esposa Angela escaparon a Jerez de la Frontera y se alojaron en casa de su amigo Juan Santiago Cerutti. ${ }^{85}$ Sin embargo, ninguno de los dos logró evitar la enfermedad. El 23 de octubre murió Angela. ${ }^{86}$ Ese mismo día Domingo hizo testamento, nombrando heredera a Úrsula Morosini, sobrina de Angela. ${ }^{87}$ También daba una ayuda económica a su criada Catalina Berruti y dejaba todos los utensilios de su oficio a Cerutti. ${ }^{88}$ Como albaceas nombraba a Antonio Sierra, conserje de la Escuela de Dibujo de Cádiz, y al propio Cerutti. ${ }^{89}$ Cuatro días después, el 27 de octubre de 1800, Domingo Álvarez fallecía en Jerez de la Frontera. ${ }^{90}$

76. Ibidem, exp. 8, carta de Domingo Álvarez, 6 de abril de 1796 .

77. Ibidem, exp. 1, carta de Antonio Font, 11 de octubre de 1796.

78. Contaba Montano: «a esta s ${ }^{a}$ [Catalina Cherubini] ay algun tiempo qe la visito una o dos veces en la semana de noche (pr que vivimos muy serca) y me edifica además de su talento en pintar, qe es un prodigio, pa ${ }^{a}$ tanta ansianidad la ql executa, pr su virtud»; ibidem, exp. 3, carta de Manuel Montano, 18 de mayo de 1796.

79. Ibidem, exp. 8, «Nota de los Dibuxos qe ha traido de Roma Dn Domingo Albarez para esta Academia de Bellas Artes».

8o. Ibidem, exp. 3, carta de Manuel Montano, 18 de mayo de 1796.

81. Ibidem, 3 de febrero de 1796 .

82. Ibidem, 6 de julio de 1796.

83. Ibidem.

84. RodríGuez Carrión, J., Jerez, 180o. Epidemia de fiebre amarilla. Jerez: Centro de Estudios Históricos Jerezanos, 1980; IgLesias Rodríguez, J.J., La epidemia gaditana de fiebre amarilla de 180o. Cádiz: Diputación Provincial de Cádiz, 1987.

85. A checklist of painters c. 120o-1994 represented in the Witt Library, Courtauld Institute of Art, London. Londres: Mansell, 1995, pág. 89. En esta obra se aporta la siguiente información: «Cerutti, Juan Santiago. Spanish (?), 18th century».

86. Domingo indicó en su testamento que había quedado «viudo en este mismo día de doña Angela Morosini»; AMJ, Protocolos notariales, José Álvarez, leg. 2975, 1798-1800, fol. 673r.

87. Orsola o Úrsula Morosini, nacida hacia 1786, era hija de Paolo Morosini, hermano pequeño de Angela, quien desempeñaba el oficio de barbero; ASVR, Stati delle anime, San Lorenzo in Lucina, 1790-1791, fol. 28r.

88. AMJ, Protocolos notariales, José Álvarez, leg. 2975, 1798-180o, fol. 675r.

89. Ibidem, fol. $673 \mathrm{r}-676 \mathrm{v}$.

90. Archivo Diocesano de Jerez (ADJ), San Dionisio, libro $5 .{ }^{\circ}$ de finados, $1784-1838$, fol. $189 \mathrm{v}$. En el acta de la Escuela de Bellas Artes de Cádiz (ARABAC, Libro de actas, acta 27, 7 de enero de 1801) se anotó por error la fecha del testamento el 23 de octubre, que es la que Huarte comunicó a la Real Academia de Madrid; ARABASF, Secretario general. Académicos por la Sección de Pintura, 1747-1856, leg. 1-49-4, s/f. De ahí pasó a la mayoría de las publicaciones. 